we can guarantee something better than by older plans, seems to me to be scarcely justifiable. Of course, if one could promise something more permanent than has hitherto been done and more nearly reaching a perfectly anatomical and functional condition then one may run the risks after explaining their possibility to the parents. As this cannot be done it is better to adhere to more gradual plans in the interests of the patients and the surgeon.

As most of the soft parts which normally help to keep the bone in place are torn through before reduction, socalled, is accomplished and as the limbs are put up at about a right angle and kept so for many months, where can the pressure of the femoral head to mould and to enlarge the acetabulum come from? And as the gaps in the torn parts are filled and they become elongated it seems to me that a loose joint, very liable to displacement in almost any direction, is made and consequently secondary displace ments-supposing a true reduction has been made-are common. Seeing that the head of the femur is larger than the acetabulum and of a different shape how can it possibly keep in place? Even by the open cutting plan when the acetabulum has been enlarged and shaped to the bead it very frequently becomes displaced on walking unless ankylosis has occurred, and as in this operation it was found to be a fault to cut the muscles, surely when they are torn through the weakening effect must be at least as great. Moreover, in the "splits" position a large part of the femoral head is downward outside the acetabulum and the small part remaining in contact, even if it do so, would need constant pressure on the sole of the foot or through the knee to produce absorption. Why Professor Lorenz prefers patients aged four years for his operation I cannot understand, for walking increases the mischief and the earlier treatment is undertaken the more hope is there for improvement.

London, W. I am, Sirs, yours faithfully, H. A. Reeves.

\section{A CASE OF HERNTA INTO THE FOSSA DUODENO-JEJUNALIS.}

To the Editors of $\mathrm{THE}$ LANCET.

SIRs,-In THE LANCET of Jan, 24th, p. 236, is a paper bearing the above title. This paper contains the record of a case of internal hernia, with comments upon the anatomical condition of the parts, but it completely ignores all the work that has recently been published upon tbis subject. The description given is clear and leaves one in no doubt that the condition found was one of left duodenal hernia. The fossa in which this hernia always lies is known as the fossa of Landzest. The fold bounding the orifire of the fossa in front is known as the plica venosa from the fact that it is raised up by the inferior mesenteric vein for which it forms in early life a sort of mesentery. There is neither need nor justification for any new term such as that suggested for the subject is already burdened by a florid and exuberant nomenclature. The hernia does not occur into the fossa duodeno-jejunalis; indeed, it is doubtful whether a hernia has ever occurred into this fossa. The probability is that the hernia is always congenital and the condition of the fossa in which it lies must therefore be studied in the foetus or the young child. When examined thus early: it will be found that a hernia into the fossa of Landzest and the fossa duodeno-jejunalis (the inferior duodenal fossa) are quite distinct. A specimen in the museum of St. Thomas's Hospital shows the hernia in an earlier stage than any other museum specimen in this country. The anatomy and surgery of the duodenal fossæ are fully discussed in the works of Jonnesco and Brösike and in my own work on "Retroperitoneal Hernia." I am, Sirs, yours faithfully,

Jan. 31st, 1903.

B. G. A. Moynihan.

\section{BRISTOL AND THE NON-VENTILATION OF SEWERS. \\ To the Editors of THE LANCET.}

SrRS, - The Bristol argument is really based on a double fallacy. The first fallacy is that the Bristol sewers are nonventilated and the exposure of this fallacy by your Special Sanitary Commissioner could scarcely be more complete. ${ }^{1}$ The second fallacy is that Brighton and Croydon are ventilated towns. This is not true, either in a legal or a sanitary sense. The Bristol position is therefore doubly false and when we consider what the practical outcome of it is, or may be, it is perniciously false.

In regard to the second fallacy your Commissioner touches the real truth when he says: "The example of Bristol seems to indicate that the ventilation of sewers has been so badly managed in some towns that Bristol without any management has obtained [health] results which are quite as good if not better." "Badly managed" is perhaps not the most appropriate term to use in the circumstances, for the trouble does not really lie in "the management" but in the means of ventilation employed in the towns misnamed ventilated.

Brighton and Croydon have been singled out as examples of ventilated towns in this discussion, I presume, because they have adopted, to a large extent at least, the high shaft system. Now, if the grid system is inadequate much more so is the high shaft system. High shafts are altogether a delusion, having not only all the faults of the grid system but in a greater degree and are therefore less efficient as a means of ventilation under all atmospheric conditions. In addition they are most expensive and unsightly and, as in the present case, fraught with public danger in the false conclusions to which they are capable of leading sanitary authorities honestly desiring to do their appointed public duty. The true inference, therefore, to be drawn from the fact that the results at Brighton and Croydon are no better than those at Bristol is that the system at Brighton and Croydon requires improvement and not that the Bristol practice should be set up as a model to be copied by other towns.

Your Commissioner's article is a most invaluable one, not only within its own limits but in the questions to which it gives rise. For example, how is it that with such a splendid public health service we are continually seeing the public health break down under severe epidemic foul air disease? I am folly convinced that the key to the answer lies in the fact that the advantages of proper sewer ventilation to public health are not yet understood by sanitary authorities. Again, how is it that after so much discussion, scientific research, and costiy experimentation the sewage disposal problem is to-day in the unsatisfactory condition it is? Again, I am convinced that the key to the answer is to be found in the fact that the solution of the sewage problem should, as I have submitted in my evidence before the Royal Commission, begin with the perfect ventilation of the sewers. Your Conmissioner, therefore, has rendered a greatly needed service to the public and I trust it will have an immediate and practical outcome, for in a few weeks the bad sewergas period will be on us again

\section{I am, Sirs, yours faithfully,}

Victoria-street, Westminster, S.W., Jan. 20th, 1903.

$$
\text { W. Brown. }
$$

\section{WHY IS NOT SMALL-POX SPEEDILY "STAMPED OUT" LIKE OTHER EPIDEMIC DISEASES? \\ To the Editors of $\mathrm{THE} \mathrm{LANCET}$.}

SIRS,-This question is often asked, yet the answer is very simple. The only true check to the spread of variola among dense communities of people is systematic and efficient vaccination of all infants and the revaccination of children at the school age. Unfortunately this disease alone of all others has been made the sport of political schemers and place-hunters who are content to sell their birthrightvaccination-for "a mess" of unseemly pottage. Yielding to the ignorant outcry against the protective influences of sterilised lymph our Government has introduced the bogey of "the conscientious objector." As a practical illustration of the advantages of intrusting compulsory powers for vaccination to a central government authority directly concerned with the maintenance of public health and the prevention of epidemic disease $I$ herewith send some details from a letter just received from a clergyman who has permanent charge of a mission station in the island of Barbados. Fortunately the authorities in this and many of our distant colonies are not fettered in their action by the wire pullers of political parties, so that whatever is really beneficent for the community can be carried out under the advice of the executive medical officers.

The Gorernment of the island, viewing with alarm the 